\title{
FORMAÇÃO DOCENTE PARA A INCLUSÃO ESCOLAR: SINGULARIDADES EXPRESSAS PELOS EGRESSOS DOS CURSOS DE LICENCIATURAS DA UFRGS
}

\author{
Julian de Camargo Milone ${ }^{1}$
}

Clarice Salete Traversini ${ }^{2}$

\begin{abstract}
Resumo: Este estudo analisa as potencialidades e fragilidades da formação dos egressos da UFRGS para a docência com alunos de inclusão escolar. Seleciona-se como lentes teóricas as noções de formação para a docência escolar e os processos de (in)exclusão na perspectiva da formação e exercício da docência. Para tanto, aplicou-se um questionário a licenciados das 15 licenciaturas da UFRGS, entre 2012/1 e 2016/2, totalizando 1655 egressos e obtendo-se o retorno de 29,8\%. Os resultados mostram que, embora classifiquem de forma positiva a sua formação para a docência, avaliam como insuficiente a sua formação para a inclusão escolar e ressaltam a importância de mais atividades práticas durante a formação. Conclui-se que, ainda que sejam oferecidas poucas disciplinas destinadas ao estudo dos processos inclusivos, os egressos idealizam o seu curso como suficiente para a completude da sua formação docente.
\end{abstract}

Palavras-chave: Licenciados. Formação docente. Inclusão escolar.

\section{TRAINING FOR SCHOOL INCLUSION: SINGULARITIES EXPRESSED BY THE GRADES OF THE LICENSEE COURSES OF UFRGS}

\begin{abstract}
This study analyzes both the potentials and weaknesses of the education of diplomaed students at the UFRGS, in particular with respect to teaching students in inclusive education. The theoretical framework employed applies ideas of education for school teaching and of the (in)exclusion process from the perspective of education and training for teaching. To this end, we carried out a study of diplomaed students in 15 undergraduate teaching courses at UFRGS between January, 2012 and February, 2016. Out of a total of 1,655 diplomaed teachers, 29.8\% responded to the study questionnaire. The results reveal that, even if these teachers rate their preparation for teaching as satisfactory, they judge insufficient their training for inclusive education, and stress the importance of increasing the quantity of practical activities in their studies. The article concludes that, even when the disciplines tailored to studying processes of inclusion are restricted in quantity, the diplomaed teachers idealize the course as sufficient for achieving their training as teachers.
\end{abstract}

Keywords: Graduates. Teacher education. School inclusion.

\section{FORMACIÓN DOCENTE PARA LA INCLUSIÓN ESCOLAR: SINGULARIDADES EXPRESADAS POR LOS EGRESOS DE LOS CURSOS DE LICENCIATURAS DE UFRGS}

\begin{abstract}
Resumen: Este estudio analiza las potencialidades y fragilidades de la formación de los egresados de la UFRGS para la docencia con alumnos de inclusión escolar. Se selecciona como lentes teóricas las nociones de formación para la docencia escolar y los procesos de (in)exclusión en la perspectiva de la formación y ejercicio de la docencia. Para eso, se aplicó un cuestionario a licenciados de las 15 licenciaturas de la UFRGS, entre 2012/1 y 2016/2, totalizando 1655 egresados y obteniéndose el retorno del 29,8\%. Los resultados muestran que, aunque clasifiquen de forma positiva su formación para la docencia, evalúan como insuficiente su formación para la inclusión escolar y resaltan la importancia de más actividades prácticas durante la formación. Se concluye que, aunque se ofrezcan pocas disciplinas destinadas al estudio de los procesos inclusivos, los egresados idealizan la licenciatura como suficiente para la completitud de su formación docente.

Palabras clave: Licenciados. Formación docente. Inclusión escolar.
\end{abstract}

Introdução

\footnotetext{
${ }^{1}$ Mestre em Educação pela Universidade Federal do Rio Grande do Sul. Técnico em Assuntos Educacionais da PróReitoria de Graduação da Universidade Federal do Rio Grande do Sul - UFRGS. E-mail: julian.milone@prograd.ufrgs.br.

${ }^{2}$ Doutora em Educação pela Universidade Federal do Rio Grande do Sul. Professora da Faculdade de Educação e do Programa de Pós-Graduação em Educação da Universidade Federal do Rio Grande do Sul - UFRGS. Integra o Núcleo de Estudos sobre Currículo, Cultura e Sociedade (NECCSO/Cnpq). Email: clarice.traversini@gmail.com.
} 
Desde meados dos anos de 1990, temos visto crescer em nosso país o estímulo à criação de políticas e leis de inclusão, especialmente a partir da Conferência Mundial sobre Necessidades Educativas Especiais de Salamanca, Espanha, em 1994. Neste encontro, 92 países, entre os quais o Brasil, tornaram-se signatários de uma Declaração que estabelecia algumas metas globais de enfrentamento da questão. Segundo Lunardi (2003), o encontro de Salamanca “[...] promoveu e estabeleceu as condições que possibilitaram a legitimidade da PNEE [Política Nacional de Educação Especial] em todo o território nacional”. A partir desta Política e da criação da então Secretaria de Educação Especial (1993), fomentou-se o espaço para o desenvolvimento da inclusão em âmbito educacional. A Lei de Diretrizes e Bases da Educação Nacional (BRASIL, 1996), a Lei de Libras (BRASIL, 2002), a Convenção da Organização das Nações Unidas - ONU, sobre Direitos das Pessoas com Deficiência (2007), a Lei Brasileira de Inclusão - LBI (BRASIL, 2015) e, ainda antes desta, o Sistema de Cotas nas Universidades Públicas Federias (BRASIL, 2012), são exemplos nacionais e internacionais de uma racionalidade globalmente difundida, que busca inserir o portador de deficiência (estendo às pessoas com insuficiência econômica e aos negros pardos e indígenas) não apenas no contexto escolar, mas também na vida social e econômica. Kraemer (2017) adverte-nos de que o Estado Brasileiro, ao investir na inclusão das pessoas com deficiências na educação regular busca promover "mecanismos para favorecer o processo de desenvolvimento da Nação". Acrescenta ainda que,

considerando que 45.606 .048 brasileiros têm algum tipo de deficiência, ou seja, 23,9\% da população (IBGE, 2010), torna-se cada vez mais determinante instituir políticas que promovam as condições favoráveis ao desenvolvimento desses sujeitos. (KRAEMER, 2017, p. 117 e 118).

Na mesma linha de compreensão da inclusão como imperativo de Estado, ao tratar do tema da inclusão, Lopes e Rech (2013) nos apresentam o conceito de in/exclusão $o^{3}$ ao tensionar a estratégia neoliberal que visa a incluir todas as pessoas no jogo do mercado, de forma que “àqueles que nem mesmo tem condições de iniciar o jogo, deve-se prover recursos mínimos que garantam pelo menos a sua entrada". Defendem que a exclusão pode ocorrer também no meio de práticas e políticas inclusivas, uma vez que essa classificação “[...] possui uma dimensão relacional" e que desta forma "[...] não pode ser capturada estatisticamente". Podemos citar, como exemplo disso, a situação de uma criança que, com algum comprometimento neurológico, é incluída na escola em atividades preparadas para sua condição de desenvolvimento cognitivo,

\footnotetext{
${ }^{3} \mathrm{O}$ termo In/exclusão, bem como o entendimento da inclusão escolar como um imperativo de Estado, vem sendo adotado por um grupo de pesquisadores do Grupo de Estudos, Pesquisa e Inclusão (GEPI/UNISINOS) sob a coordenação da Prof $^{a}$. Dr ${ }^{a}$. Maura Corcini Lopes ao trabalhar com a perspectiva da inclusão a partir dos Estudos de Michel Foucault.
} 
mas que, entretanto, é excluída das avaliações em larga escala por não ter condições de compreender e responder a uma prova escrita.

Em outras palavras, "[...] in/exclusão aponta para o fato de que as atuais formas de inclusão e de exclusão caracterizam um modo contemporâneo de operação que não opõe a inclusão à exclusão" (VEIGA-NETO; LOPES, 2007, p. 130). Dialogando com os autores, consideramos que "[...] ao invés de imaginar uma sociedade com plena inclusão, compartilhamos da perspectiva que a inclusão e a exclusão são parte do mesmo processo" (TRAVERSINI, 2011), uma vez que os sujeitos, em suas possibilidades de participação, estarão incluídos ou excluídos, conforme a exigência da atividade a ser desempenhada ou vivenciada. Nesse sentido, cabe questionar como podemos falar em inclusão e exclusão nas práticas escolares, uma vez que todos os sujeitos podem estar incluídos e excluídos em alguma medida. Entendemos que a inclusão escolar está posta como uma ferramenta que visa a enquadrar o que é anormal dentro da norma escolar e, desta forma, desenvolver atividades escolares para os alunos tidos como "normais" e "anormais" dentro da normatização escolar. Segundo Veiga-Neto e Lopes (2007) "acontece uma normalização disciplinar quando se tenta conformar as pessoas - em termos de seus gestos e ações - a um modelo geral previamente tido como a norma", de modo que suas ações possam ser conformadas dentro de uma realidade, de um ambiente, neste caso, o escolar. Dizem ainda os autores que, "assim, é dito normal aquele que é capaz de amoldar-se ao modelo e, inversamente, o anormal é aquele que não se enquadra ao modelo" e que, desta forma, a norma funciona como "um princípio de comparação, de comparabilidade, de medida comum, que se institui na pura referência de um grupo a si próprio, a partir do momento em que só se relaciona consigo mesmo" (Idem, 2007, p. 956). Desta maneira, aquilo que classificamos como normal e anormal está dentro desta "régua" de comportamentos possíveis e que são definidos à medida que se aproximem mais ou menos, respectivamente, do padrão central da norma. Este cenário do imperativo neoliberal da inclusão escolar é importante para entender o processo histórico dos últimos 30 anos em que tal racionalidade inclusiva atinge seu grau de maturidade na escola, de modo a não mais ser possível aceitar, socialmente, que a qualquer pessoa - qualquer que seja sua limitação - seja negado o direito à inclusão escolar.

Posto isso, diante deste imperativo da educação inclusiva, que a coloca na condição de "uma das principais diretrizes das políticas públicas educacionais realizadas em nosso país nos últimos anos" (FERREIRA; GLAT, 2003, p. 380), é preciso, conforme referido por alguns estudos (MENEZES, 2011; SÁNCHEZ, 1996; FABRIS, 2011; BRABO, 2013), ampliar e reestruturar a formação de professores no ensino superior, em nível de graduação e de forma continuada, a fim de dar-lhes subsídios e condições para a realização de seu trabalho junto aos alunos de inclusão. 
Desta forma, esta pesquisa teve como foco analisar a formação dos egressos licenciados pela UFRGS a fim compreender como percebem as potencialidades e fragilidades de sua formação para a educação inclusiva.

\section{Procedimentos metodológicos da pesquisa}

A pesquisa foi realizada junto aos egressos dos 15 cursos de licenciaturas da UFRGS, uma vez que, ao abranger a totalidade dos cursos de formação de professores, possibilitaríamos um retorno maior de respondentes, de forma a tornar mais profícuas as análises do material produzido. Optamos, no entanto, por pesquisar os egressos apenas dos cursos oferecidos na modalidade presencial, por entender que poderia haver uma variabilidade muito grande e de difícil análise ao misturar ambas as modalidades. Utilizamos como critério para o envio dos questionários (em janeiro de 2018) os egressos formados até 2016/2, a fim de permitir um período de pelo menos um ano para que estes formandos pudessem estar inseridos no mercado de trabalho escolar. Já para o período inicial de egressos pesquisados foi estabelecido o semestre de 2012/1, tendo em vista que, em 2008 a UFRGS instituiu o seu próprio Programa de Cotas para o acesso de candidatos negros, pardos e indígenas, além de oriundos de famílias com renda inferior a 1,5 salários mínimos. Esta escolha reforça-se pelo entendimento de que as experiências de vida destes sujeitos cotistas, anteriores ao ingresso na universidade, bem como sua presença em seus cursos de licenciaturas, podem ter fomentado, de alguma forma, experiências diferenciadas para a formação docente destes estudantes e de seus demais colegas com vistas à inclusão escolar. A partir destas escolhas metodológicas, o questionário foi enviado a 1655 egressos que receberam, através de mensagens de e-mails, o convite para participar da pesquisa. A participação foi realizada mediante o preenchimento de um questionário por meio virtual, através do aplicativo Google Forms. Afortunadamente, ao final do período de respostas, que permaneceu aberto por 45 dias, obtivemos o retorno de 483 participantes, o que representa $\mathbf{2 9 , 8 \%}$ do total de egressos convidados a participar da pesquisa.

O questionário continha uma primeira parte, com sete questões, destinadas à coleta de informações gerais, nas quais foram solicitados o nome, a idade, o curso, o ano de ingresso e de conclusão, o local de trabalho e o tempo de atuação como professor, quando fosse o caso; uma segunda parte, elaborada através da metodologia da escala de Likert, que apresentava seis proposições para as quais o respondente deveria selecionar uma delas (onde 1 representava sua discordância plena e 5 sua concordância plena), de forma a avaliar questões em relação à formação curricular (quatro relativas à formação geral, intercaladas por duas relativas à formação para as dificuldades de aprendizagem); e uma terceira e última parte, composta por uma pergunta 
no formato aberto, de forma que o entrevistado pudesse expressar-se sobre algo acerca de sua formação que não tivesse sido questionado.

Com relação à segunda parte do questionário, que corresponde às questões apresentadas através da escala de Likert, Costa e Júnior (2014) nos informam que a escala desenvolvida pelo pesquisador Rensis Likert consiste em um questionário em "[...] que se toma um constructo e desenvolve-se um conjunto de afirmações relacionadas a este constructo" (COSTA; JÚNIOR, 2014, p. 4). Neste caso, os constructos utilizados foram em relação à segurança dos egressos mediante sua formação para o exercício da docência e a presença da temática da inclusão nesta formação. Segundo os autores, pela “[...] confirmação de sua consistência métrica, o método da escala de Likert tem sido muito utilizado nas mais diversas áreas do conhecimento, inclusive nas ciências humanas" (COSTA; JÚNIOR, 2014, p. 4), como é o caso desta pesquisa.

\section{Características dos egressos participantes}

A primeira questão do formulário apresenta-nos os nomes dos participantes e, a segunda, nos traz um panorama de suas idades. Neste aspecto, houve uma participação maior do grupo que possui idades entre 26 e 30 anos, com um percentual de $39,1 \%$, ou seja, praticamente $20 \%$ a mais do que os demais intervalos de idades sugeridas (20 a $25-15,5 \%$; 31 a $35-22,8 \%$; mais de $35-22,6 \%$ ). Como a pesquisa foi enviada aos egressos de 2012 a 2016, essa concentração etária nos leva a considerar que a maior parte dos egressos tenham ingressado na Universidade com idades entre 18 e 24 anos. Isso reforça o aumento dos dados de ingresso de estudantes entre 18 a 24 anos no ensino superior até 2016 que, conforme o PNAD/IBGE (IBGE, 2017), alcançou seu ápice de 23,8\% de frequência líquida, nesta faixa etária, no nível de ensino superior. Taxa que, no entanto, ainda está aquém dos 33\% desejados pela meta 12 do Plano Nacional de Educação 2014-2024.

A terceira e quarta questões tratavam, respectivamente, dos anos de ingresso e conclusão de curso por parte dos participantes da pesquisa. E, a esse respeito, obtivemos o retorno de que quase $60 \%$ deles ingressaram em seus cursos antes de 2010. Contudo, se olharmos para a resposta seguinte sobre o ano de conclusão, veremos que foi mais distribuída entre 2012 e 2016 (gráfico 1), o que nos permite inferir que, dos ingressantes antes de 2010, 40\% deles levaram 5 anos ou mais para concluírem seus cursos de licenciatura. 


\section{Gráfico 1}

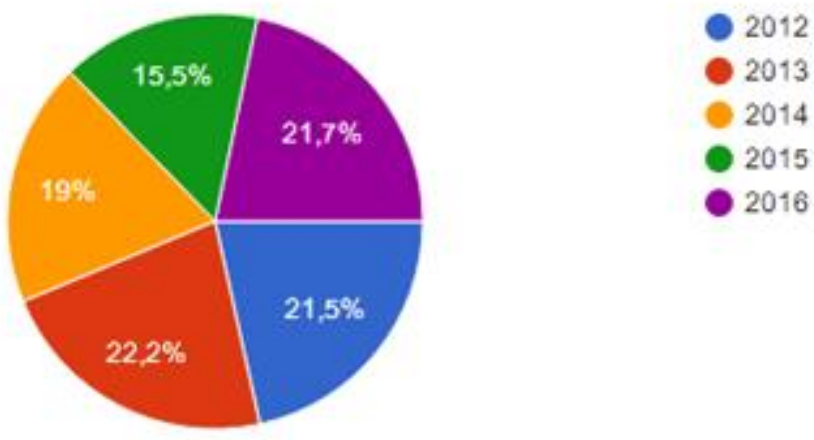

Isto parece indicar a necessidade dos estudantes de permanência por mais tempo em seus cursos para conseguirem cursar as atividades de ensino e/ou aproveitar melhor as oportunidades de ensino, pesquisa e extensão oferecidas pela Universidade, possivelmente pelo perfil de aluno trabalhador que temos nos cursos de licenciaturas. Vargas e Paula (2013) defendem que as universidades federais brasileiras, em que pese a intenção de ampliar o acesso a todas as camadas sociais e a um número muito maior de brasileiros, não favorecem a permanência dos estudantes trabalhadores. Isto porque mantêm poucos cursos noturnos e uma distribuição de disciplinas nos diferentes turnos, o que leva nossos estudantes a se formarem em um período de tempo maior do que o estimado pelos currículos de seus cursos.

A quinta questão, solicitava aos participantes que mencionassem o seu curso de licenciatura cursado na universidade e, para esta questão, obtivemos uma distribuição semelhante entre os cursos, em percentual correspondente ao número de vagas ofertadas. Na sexta questão (gráfico 2), foi questionado o local de trabalho e, dos 483 respondentes, 32,2\% disseram estar trabalhando em escolas públicas; 20,3\%, em escolas privadas; 6,4\% em ambas, pública e privada. Apesar de o senso comum, entre professores e alunos da UFRGS, sugerir que esta seja uma instituição que forma mais alunos para a rede particular do que para a pública, os dados em que pese haver uma oferta maior de vagas na rede pública do que na privada - revelam que nossos egressos estão em maior número trabalhando na rede pública de ensino. Maciente et. al. (2015) demonstram - através de estudo realizado em âmbito nacional com os estudantes graduados em licenciaturas e engenharias no ano de 2011 - que, em 2012, os licenciados diferentemente dos egressos de cursos de engenharias, cujos salários são melhores do que os de seus pares formados em instituições de menor prestígio -, não possuíam salários distintos de seus pares em função da qualidade de seus cursos de formação. Este pode ser um dos motivos pelos quais os alunos da UFRGS - em que pese a avaliação do IGC a apontá-la como a melhor Universidade na categoria "ensino" dentre as federais - estejam trabalhando no ensino público 
por uma oferta salarial inferior a de seus pares de outras instituições de ensino. É possível, por esse mesmo motivo, que muitos deles evadam a carreira docente nos primeiros anos de formação, como no caso dos $22 \%$ que disseram não estarem trabalhando no ambiente escolar, mas em outras oportunidades voltadas à atuação docente ou à formação de pós-graduação. Preocupante foi o dado de que $19,1 \%$ deles relataram estar desempregados no momento, por mostrar uma difícil realidade da falta de emprego depois de formados, pelo menos com pouca experiência profissional. Maciente et. al. (2015) demonstram em seu estudo que, neste aspecto, $71 \%$ dos licenciados estavam empregados em áreas afins à sua área de formação e que isto guarda correlação estatística com cursos mais procurados como as engenharias. Desta forma, o dado encontrado em nossa pesquisa, que revela o desemprego de 19\% dos nossos egressos, está dentro e aquém do cenário nacional apresentado por Maciente et. al. (2015). Isso nos sugere que, mais do que uma dificuldade dos egressos da UFRGS, a dura realidade do desemprego seja comum para os sujeitos graduados nas Universidades de todo nosso país.

\section{Gráfico 2}

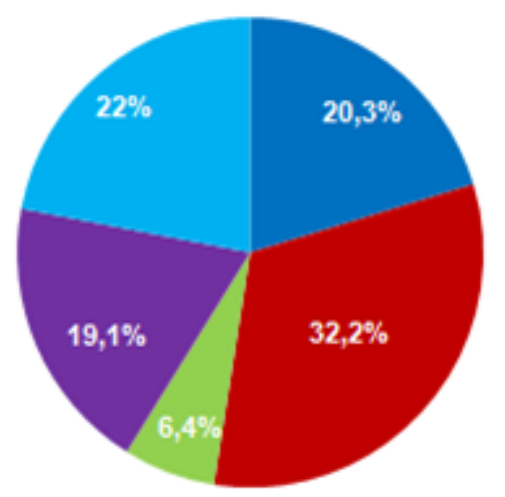

- escola pública

escola privada

escolas pública e privada

- Desempregados

- Outras atividades profissionais

$\mathrm{Na}$ questão 7, quanto ao período em que estão atuando como professores nas escolas, a maioria declara possuir até 2 anos de experiência (36\%). No entanto, 26,9\% dos participantes, relatam já ter uma experiência de mais de 6 anos na atividade docente nas escolas em que atuam, o que reforça a conclusão de que boa parte de nossos estudantes se divide entre a formação e o trabalho. Esta realidade tornou-se mais comum, segundo Vargas e Paula (2012), com a implantação de programas como o PROUNI de 2004 (bolsas de estudo em instituições privadas de ensino superior), o REUNI de 2007 (Programa que acelerou a oferta de vagas nas instituições públicas de ensino superior, especialmente as noturnas) e a Lei de Cotas de 2012, que ampliou o acesso a alunos de escolas públicas, de baixa renda e a negros, pardos e indígenas. No entanto, faz-se importante ressaltar que nesta pesquisa avaliamos apenas os egressos que trabalhavam como professores, o que pode representar uma pequena parcela, se pensarmos que existem outras 
formas de atuação profissional possíveis aos nossos estudantes durante sua formação, além da docência. Destarte, os achados desta parte da pesquisa com os egressos, apresentam, em síntese, jovens entre 18 e 24 anos, que trabalham durante a graduação e que, licenciados, começam a sua carreira docente em escolas públicas.

\section{Formação para a docência inclusiva na licenciatura}

Na segunda parte do questionário, em que as questões foram dispostas através do método da escala de Likert, avaliamos a compreensão que os sujeitos da pesquisa fazem de seu processo de formação docente e especificamente para a docência inclusiva. Para tanto, as questões lhes ofereciam uma escala de 1 a 5 em que 1 consiste na discordância plena e 5 na concordância plena à afirmação realizada na questão. Desta forma, na questão 8 (gráfico abaixo), em que lhes é afirmado que sua atividade como professor está fortemente relacionada à sua formação na UFRGS, 68,8\% deles concorda muito ou plenamente com essa afirmação, enquanto que apenas 13,2\% discordam muito ou plenamente da afirmação.

\section{8 - Minha atividade como professor(a) está fortemente relacionada à minha formação na UFRGS:}

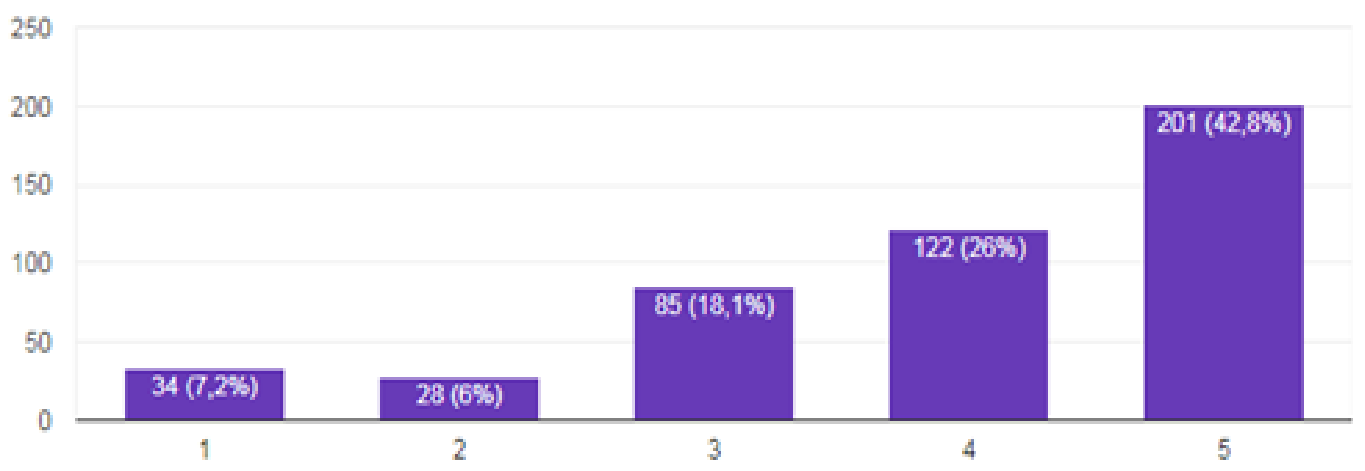

Com relação à questão 9, ao afirmar que os egressos se sentem preparados para exercer a docência a partir da formação recebida na UFRGS, 62,8\% deles concordam muito ou plenamente com essa afirmação e apenas 11,8\%, discordam muito ou plenamente da afirmação.

A união destas duas questões (constructos 8 e 9), nos permite considerar que os egressos da UFRGS se sentem seguros e fortalecidos em sua atuação profissional, a partir da formação recebida em seus cursos de licenciaturas. E, em que pese na questão aberta, mencionem muitas dificuldades e fragilidades no ensino recebido em seu curso, manifestam que, de maneira geral, sentem-se bem formados para sua atuação docente. 
Entretanto, na questão 10 que lhes é afirmado que o currículo do curso de graduação forneceu subsídios para trabalhar com alunos com dificuldade de aprendizagem, 58,8\% dos respondentes discordaram muito ou plenamente da afirmação e apenas $23,7 \%$ concordaram muito ou plenamente. Nesta questão, tivemos ainda um percentual de 27,7\% que optou pela alternativa 3, que representa a indiferença em relação à afirmação. Estes percentuais assemelham-se aos que, na questão 11, discordam da afirmação de ter havido, nos planos de ensino das atividades de ensino, questões relativas às dificuldades encontradas pelo professor para trabalhar com alunos com dificuldades de aprendizagem. Nesta afirmação tivemos 47,2\% dos respondentes discordando muito ou plenamente da afirmação, e apenas 22,2\% concordando muito ou plenamente com o afirmado.

\section{1 - Os Planos de Ensino das disciplinas do meu curso de graduação envolveram questões relativas as dificuldades enfrentadas pelo professor da educação básica frente à diversidade cognitiva de seus alunos.}

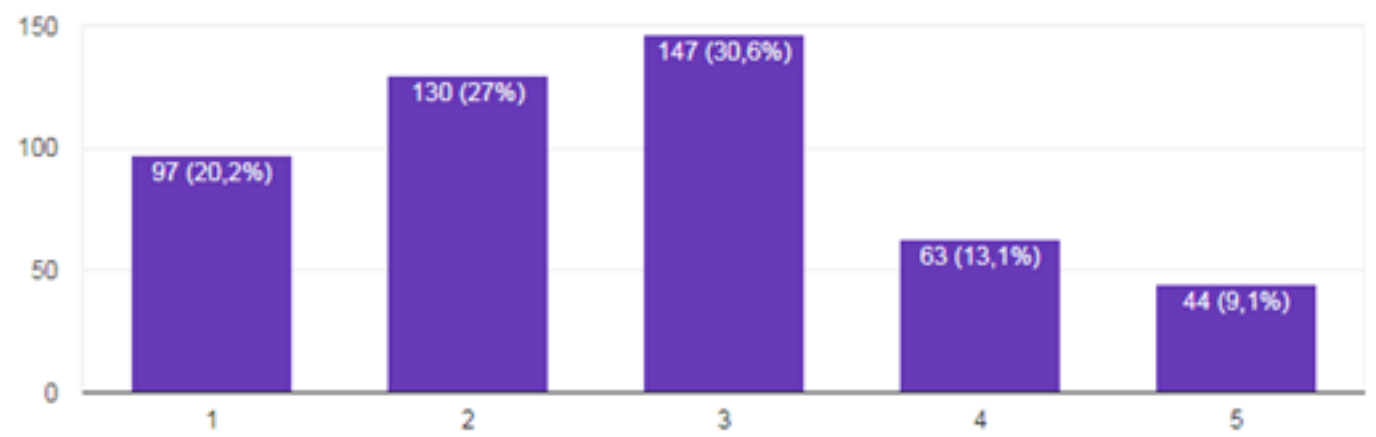

Importante destacar que no constructo 10, ao utilizarmos a expressão "dificuldades de aprendizagem", em vez de "alunos incluídos", fizemo-lo pelo fato de que, inicialmente, cogitávamos estudar os alunos com dificuldades de aprendizagem, especificamente, o que são conceitos complexos e diferentes entre si. Isso representa uma limitação da pesquisa em relação à proposição das questões.

A relação entre as questões 10 e 11 nos permite considerar (ressalvado o equívoco metodológico acima citado) que os egressos da UFRGS, apesar de sentirem-se seguros para trabalhar com a docência escolar (questões 8 e 9), em sua ampla maioria afirmam que os currículos de seus cursos não os formaram suficientemente bem para trabalhar com as dificuldades de aprendizagem de alguns de seus alunos em sala de aula. Ao propor a análise da formação, nesta questão, através do termo "formados suficientemente bem”, lançamos mão de 
uma expressão que busca conduzi-los ao objetivo da questão, que é avaliar como eles valoram o seu aprendizado para a docência. Isto é, embora compreendamos que não exista formação absoluta e que tampouco se pretenda valorar o que serve e o que não serve, precisávamos encontrar um canal mais preciso de comunicação da questão com o sujeito pesquisado.

Outro dado importante, ainda sobre as questões 10 e 11, diz respeito ao fato de que houve, em ambas as questões, uma quantidade significativa de alunos (e semelhante: 27,7\% e $30,6 \%$ ) que ficaram indiferentes a estas duas afirmações. Isto pode ser um indicativo de que os alunos se sentiram pouco confiantes para responder a esta questão, o que permite levantar a hipótese de que o conteúdo foi trabalhado nas atividades de ensino, mas de forma insuficiente.

$\mathrm{Na}$ questão 12, afirma-se que foram realizadas atividades práticas que forneceram segurança para sua atuação como professor e, nesta, 62,2\% concordaram muito ou plenamente com a afirmação, frente a apenas $16,6 \%$ que discordaram muito ou plenamente.

12 - Realizei atividades práticas ao longo do meu curso de graduação que forneceram segurança para a minha atuação como professor.

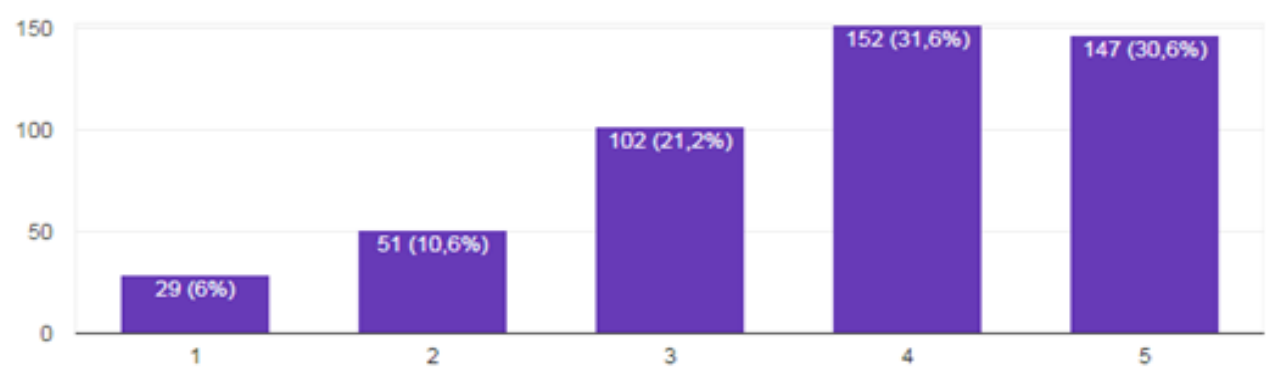

No constructo 13, os respondentes receberam a afirmação de que tiveram, ao longo de seu curso, preparação adequada para sua atuação como professor. E, para este item, 56,7\% concordaram muito ou plenamente com a afirmação e apenas 15,9\% discordaram muito ou plenamente da afirmação. Faz-se oportuno salientar que este item teve como objetivo especular o quanto os alunos se sentem confiantes diante de sua formação, tendo em vista que não há como mensurar o que signifique, para cada um, uma "preparação adequada" para a prática da docência escolar. Nóvoa (2009) destaca ser “impossível definir o ‘bom professor', a não ser através dessas listas intermináveis de 'competências', cuja simples enumeração se torna insuportável” e que vão estabelecendo a equivocada sensação de completude da formação. $\mathrm{O}$ autor destaca, ainda, que embora "o domínio científico seja imprescindível para a formação", esta se concretiza apenas quando "construída dentro da profissão", isto é "baseada numa combinação complexa de 
contributos científicos, pedagógicos e técnicos, mas que tem como base os próprios professores" (NÓVOA, 2009, p. 216). Desta forma, ainda que percebam uma forte contribuição para sua formação, não há como mensurar o que seja para cada egresso a tal formação adequada e menos ainda pensar que ela seja homogênea entre eles.

De forma geral, ao descrever o conjunto de seis constructos solicitados no questionário aos egressos, embora 62,8\% dos participantes afirmem sentirem-se "bem formados" para o desenvolvimento da docência escolar (item 9), 48,6\% afirmam que o curso não desenvolveu conhecimentos, tidos por eles como suficientes, para trabalhar com os alunos com alguma dificuldade de aprendizagem. E, dentre esses, encontram-se os alunos incluídos, tendo em vista que significativa parcela deles nas escolas possuem dificuldades de aprendizagem.

Interessante observar que pesquisas sobre formação docente para a inclusão, como as de Terra e Gomes (2013) com professores da educação básica da rede pública de Minas Gerais; de Poulin e Figueiredo (2016) sobre os estudos de formação inicial dos professores para a atuação em contextos de educação inclusiva, nacionais e internacionais; e de Poker, Valentin e Garla (2018) com professores universitários do Estado de São Paulo, evidenciam que, nos diferentes segmentos de atuação profissional, os docentes sentem-se com formação incipiente, o que os leva à insegurança para fazer propostas de aprendizagem com os estudantes incluídos. Não advogamos neste texto que a formação docente é algo finito e que após concluir a licenciatura o professor deva sentir-se em condições de assumir qualquer aluno de inclusão. Defendemos, diferentemente, que a realização de processos de aprendizagem com alunos incluídos, em qualquer nível de ensino, é um desafio constante para o qual formação alguma se torna suficiente. Há uma miríade de nuances que caracterizam os sujeitos incluídos na escola e na universidade. Fabris (2011) destaca a importância da formação docente constante, seja para aprofundar conhecimentos das várias áreas de conhecimento, seja para inventar estratégias pedagógicas para potencializar as aprendizagens considerando que na sala de aula convivem grupos heterogêneos de alunos.

\section{Singularidades na formação docente segundo os licenciados}

O espaço aberto da última questão do formulário foi elaborado com a intenção de oportunizar um ambiente de fala qualitativa ao egresso. Assim, foi proposto que escrevessem através da seguinte questão: "Caso haja algum comentário a respeito de sua formação como professor, que não tenha sido perguntada no formulário, mas queira fazer o relato, utilize o espaço abaixo". Desta forma, o espaço foi de suma importância, pois nele encontramos elementos, falas constitutivas do sujeito, que contribuíram para a análise das singularidades quanto à formação acadêmica dos sujeitos desta pesquisa. Ademais, destacamos a importância 
desta questão como um espaço - um lugar de fala - em que o egresso pôde escrever livremente sobre aquilo que desejasse diante do tema da pesquisa. Nesta questão eles puderam expressar-se para além de questões de múltipla escolha, demonstrando seu sentimento e suas opiniões em relação ao curso e à Universidade em que se formaram professores. É com esta interpretação que lemos os comentários, tendo a convicção de que cada um representa um pouco daquilo que pulsa no sujeito em relação à sua condição de egresso de um curso de licenciatura da UFRGS.

Inicialmente, separamos os comentários a partir de uma análise quanto ao tipo de expressão, como uma potencialidade (aspecto positivo) ou como uma fragilidade (aspecto negativo) relativa ao percurso formativo destes alunos. Após, a partir da ocorrência, dividimo-las quanto ao seu tema (currículo, planos de ensino, atividades práticas, estágios, iniciação à docência, pesquisa e extensão), no intuito de perceber a recorrência de cada um deles. Dos 483 respondentes do formulário, obtivemos 118 respostas textuais neste campo que, reiteramos, não era um campo obrigatório. Destas 118 respostas, ou seja, 24,9\% dos respondentes do formulário, 31 interpretamos que "não se aplicaram" ao tema da pesquisa por fazerem menção a questões que não diziam respeito ao tema proposto. Já, 87 respostas textuais versavam sobre o tema do estudo e foram classificadas, conforme descrito acima. Destas $87, \mathbf{5 5}$ foram classificadas como fragilidades encontradas na fala dos sujeitos e $\mathbf{3 2}$ como potencialidades elencadas pelos egressos neste campo textual. Abaixo, apresentamos o resultado desta pesquisa com excertos das respostas de forma a explicitar o teor e a intensidade de algumas destas falas. Das 55 fragilidades, há repetição de temas, os quais foram agrupados por proximidade de informação nos seguintes aspectos:

- Fragilidade didática: 17 ocorrências

"A grande maioria dos professores da graduação não tem muita experiência em escola regular, ensino fundamental e médio, e isso acaba por deixar a nossa formação muitas vezes no plano da suposição, do imaginário... Gerando insegurança quando vamos para sala de aula."

"Temos uma formação muito voltada para a teoria, não conhecemos a realidade das escolas, sobretudo das escolas públicas, o que dificulta a prática quando iniciamos a ser professores."

Licenciado 179

- Fragilidade na distribuição das Atividades de Ensino no Projeto Pedagógico do

Curso: 8 ocorrências

"Penso que a disciplina sobre Educação especial e inclusiva, que fica no mesmo semestre que o TCC, poderia ser anterior a este momento de TCC para que se possa ter maior dedicação com a mesma já que no momento de TCC nos dedicamos muito a ele."

Licenciado 313 
- Falta de Atividades de Ensino sobre inclusão escolar: 8 ocorrências

"Durante minha formação, não tive nenhuma cadeira que tratasse da educação especial; pelo menos, nada além da citação de uma lei. Nas escolas municipais, onde atuo, há muitos casos desse tipo, sobretudo, deficiência intelectual, e não me sinto preparada para trabalhar com isso."

Licenciado 395

Das 32 potencialidades, há recorrência nos seguintes temas:

- Relevância de bolsas, estágios, pesquisa e extensão na formação: 19 ocorrências

"Minha participação no PIBID acabou fazendo com que eu aprendesse e praticasse muitas questóes relacionadas à docência. Penso que foi meu interesse pela docência e minha inserção no referido programa, que auxiliaram em minha qualificação profissional e pessoal."

Licenciado 224

- Estrutura curricular com ênfase em práticas didáticas: 8 ocorrências

"Há disciplinas e professores maravilhosos na área da (...) na UFRGS. Que super estimularam a discussão, reflexão, pensamento crítico. No entanto, muitos outros não infelizmente. Na (...), ao menos na minha época e no meu ponto de vista, possuía muitas disciplinas um tanto redundantes em termos de conteúdo trabalhado, bem como condução das aulas. O que considero que realmente me ajudou, afora as raras disciplinas e professores mega competentes, foi a prática didática juntamente com a discussão em grupo (uma espécie de terapia de grupo), e o acompanhamento aula a aula pelas professoras. Isso ajudou imensamente para ganhar experiência e confiança."

Licenciado 34

"Iniciei meu curso de graduação junto com a minha atuação profissional na rede pública... tive a oportunidade de constantemente relacionar teorias e prática, mas sempre pensei que para quem não teve essa oportunidade fazem falta as oportunidades práticas no curso"

Licenciado 06

- Formação continuada: 3 ocorrências

"Após minha formação na graduação, participei do Programa de Educação Continuada do Colégio de Aplicação da UFRGS, atuando como professora durante um ano dando aula a uma turma de $9^{\circ}$ ano. Com certeza, essa prática docente me forneceu muito mais experiência para atuar como professora, principalmente em relação aos problemas cognitivos dos alunos e em relação a situações de indisciplina em sala de aula."

Licenciado 260

As escritas dos egressos nas questões abertas, por nós organizadas, apresentam, no que tange às fragilidades, a existência de algumas lacunas nos conteúdos de formação docente, como quando declaram não terem tido disciplinas suficientes, bem como Planos de Ensino nestas disciplinas que os mobilizassem à educação inclusiva, tornando necessária a busca por outras formas de aprendizagem em relação a esta temática. Mas, seria uma falta de conteúdos na 
formação de licenciatura, ou um processo formativo iniciado na graduação e que necessita de continuidade no exercício da docência? Entendemos que esta dúvida incite a continuidade de outros estudos qualitativos, a fim de não apenas analisar, mas compreender como o sujeito licenciado percebe sua constituição na formação docente inclusiva para o desafio de trabalhar com a in/exclusão escolar.

Se nos ativermos às potencialidades, perceberemos que boa parte dos egressos participantes alega ter sido fundamental em sua graduação a busca por atividades complementares às de ensino para sua formação, tais como a pesquisa, a extensão e, principalmente, as atividades de estágio e iniciação à docência. Tais constatações são reforçadas pelos estudos de Nóvoa (2009) e Fabris (2011) de que a formação é contínua e se complementa pelo exercício da docência, tendo o próprio professor como parte ativa de sua formação. $\mathrm{O}$ desenvolvimento destas atividades oportuniza uma experiência do sujeito entre teoria e prática, numa relação de aproximação, reflexão e problematização em sala de aula, dos conhecimentos que produziram ao longo da formação de licenciatura. Esta questão é extraída na primeira unidade separada dentre as fragilidades, em que os alunos mencionam em 22 ocorrências a falta de atividades práticas. Ao somarmos estas 22 ocorrências às 19 das potencialidades relativas a bolsas e estágios, temos 41 ocorrências sobre esta questão, especificamente, o que representa, no universo das 87 opiniões validadas para a análise, $46 \%$ das ocorrências. E este é o ponto fulcral que emerge desta pesquisa de forma mais latente, qual seja o forte teor que as experiências vividas por estes egressos podem ter sobre sua constituição docente. Isto é, daquilo que esteja "tocando" (LARROSA, 2002) o indivíduo como um sujeito marcado pela experiência na formação docente. Utilizo-me da expressão experiência no sentido atribuído por Jorge Larrosa ao mencionar que experiência é tudo aquilo "que nos passa, que nos acontece, que nos toca" em que o sujeito da experiência "seria algo como uma superfície sensível" onde as relações que se produzem com o outro o "afetam de algum modo, produzem alguns afetos, inscrevem algumas marcas, deixam alguns vestígios, alguns efeitos". O sujeito, nesta relação seria como "um ponto de chegada, um lugar a que chegam as coisas e que, ao receber, lhe dá lugar". (LARROSA, 2002, p.23). Amparado por esta profundidade que a experiência produz no sujeito licenciado, faz-se importante buscar na memória destes sujeitos egressos, não apenas os conteúdos, mas a relação destes com as experiências formativas que os constituíram como docentes.

\section{Considerações Finais}

Diante do objetivo de analisar as potencialidades e fragilidades expressas pelos egressos sobre sua formação docente de licenciatura, percebe-se que há um perfil de estudante atualmente, bastante heterogêneo - que ingressa na Universidade, em sua maioria, entre 18 e 24 
anos, na direção do pretendido pela meta 12 do PNE. Apresenta-nos, a pesquisa, um sujeito graduando de licenciatura que, pelo perfil atual de nossos ingressantes, necessita dividir o período de estudos com a jornada profissional, o que acarreta experiências profissionais que implicam a formação, sua e dos seus colegas, mas que, ao mesmo tempo, torna o seu percurso formativo um pouco mais lento do que a previsão da grade curricular de seu curso. Destaca-se que estes estudantes vislumbram uma formação na graduação que pela possível excelência, seja suficiente para a completude do exercício de sua profissão docente, embora várias de suas falas remetam ao sentimento de que o curso não os preparou para trabalhar com os alunos de inclusão. Nas análises realizadas não buscamos compreender se havia formação para o licenciando desenvolver sua docência somente com alunos incluídos - como ocorre nos Laboratórios de Aprendizagem com o Atendimento Educacional Especializado. Nosso objetivo foi de compreender se, na trajetória do curso de graduação de licenciatura vivenciado pelo licenciado, havia formação para trabalhar com alunos incluídos, seja por questões cognitivas, físicas ou sociais, nas turmas regulares da educação básica. A pesquisa mostra ainda que pouco menos da metade continua seu percurso de formação em pós-graduação, ou busca outra atuação profissional e ainda que apenas com a graduação não encontra empregabilidade na docência escolar.

Quanto à formação para a docência inclusiva, percebemos egressos que defendem não terem sido devidamente estimulados em relação à educação inclusiva, mas que acreditam ter uma formação adequada para a docência escolar de modo mais amplo. Essa compreensão dos estudantes resulta muito da perspectiva do olhar governamental para as políticas públicas para a educação inclusiva, como no Plano Viver sem Limites do Governo Federal (BRASIL, 2013) que evidenciam a necessidade de salas multifuncionais e transporte adequado, mas pecam nas propostas e condições para a formação de professores para esta realidade. Esse descompasso nas respostas leva-nos a considerar que os egressos, imersos que estão na racionalidade da produção e do profissionalismo exacerbado, e pela falta de uma estrutura pedagógica para a compreensão das particularidades da educação inclusiva - como se esse fosse o único objetivo de uma formação acadêmica -, estejam mais focados e preocupados em transmitir o conteúdo específico de sua formação de licenciatura, do que em se colocar no lugar do outro (aluno) para compreender como este sujeito "aprende". Ademais, ao separarem a "formação docente" da formação para a educação inclusiva, já demarcam uma segregação destes alunos de inclusão como algo exterior ao processo educativo. Entendemos que a educação necessita ser um espaço de alteridade em que os sujeitos sejam, por sua heterogeneidade, respeitados em suas diferenças. Assim a necessidade de olhar os alunos como sujeitos de inclusão estará engendrada no processo educacional. Ao compreendermos que a escola é um espaço de constante inclusão de todos e não 
apenas de quem possua alguma patologia ou deficiência, não haveria a necessidade de compreender este trabalho fora do âmbito das atribuições profissionais da docência, portanto, também não haveria a necessidade de compreender este trabalho como externo ao processo de formação docente. Entretanto, ainda que não tenhamos chegado a este patamar de racionalidade inclusiva, faz-se imprescindível questionar se os estudantes de licenciatura compreendem que uma disciplina não precisa levar, necessariamente, o termo "inclusão" em seu nome para tratar da temática, bem como não possa ser deslocada a compreensão da alteridade e do respeito às diferenças em qualquer que seja a prática ou teoria de formação docente.

Depreende-se das falas destes egressos a inquietude da falta de um "produto" específico de formação, que se possa definir como algo que "foi aprendido" na graduação e que agora pode, no âmbito profissional, ser ofertado, transmitido e/ou comercializado, assim como o têm os dentistas, arquitetos, médicos, profissionais que veem a aplicabilidade de seus conhecimentos de forma mais concreta no mercado de trabalho, ao lidar com questões mais pontuais e fluídas. A educação, a produção de conhecimentos e as noções de vida, de liberdade, de autonomia, de responsabilidade com as quais o professor lida cotidianamente na vida educacional de uma pessoa, seja ela uma criança ou um adulto, oferecem muitos desafios por não serem produtos acabados e aplicáveis concretamente. Essa concepção se depreende do conjunto de falas que vão mais ao encontro de um sujeito professor que tende à simples transmissão de conteúdos, numa compreensão profissional - imersa na racionalidade neoliberal da produção e do consumo - que busca do dever cumprido. Ao contrário de um sujeito preocupado com o aluno - como alguém a quem precisa conhecer, reconhecer, trocar experiências, suscitar vontades e desejos, seduzir e auxiliar na aquisição de conhecimentos. Concepção que remete também aos que pensam não terem sido formados para a docência inclusiva por terem cursado não mais do que uma disciplina específica para esta temática, o que, retomando o discurso da "sapiência universal" de Fabris 4 (2011, p. 33), permite-nos crer que esperavam concluir o seu curso de graduação "sabendo tudo" sobre a temática da inclusão escolar, foco deste estudo.

Diante desta formação que avaliam os egressos como excelente no geral, mas insuficiente no que tange à inclusão escolar, às atividades práticas e a alguns conteúdos relativos ao ensino e à aprendizagem, torna-se instigante compreender, através da continuidade destes estudos, como estes sujeitos constituíram-se docentes nesta caminhada formativa para além do terreno da graduação. Tendo em vista, como salienta Nóvoa (2009) que o professor continua em processo

\footnotetext{
${ }^{4}$ Fabris (2011), ao realizar uma pesquisa junto a docentes de uma escola do Município de São Leopoldo, descreve que "uma das maiores queixas das professoras dessa escola era a falta de preparação para trabalhar com alunos com necessidades especiais. Ao fazer este relato, no entanto, tensiona esta fala das professoras ao manifestar que parece haver um senso comum de que o professor possua uma "sapiência universal, talvez pelo significado cultural que posiciona o docente como alguém que sabe porque ensina e que, por isso, precise e deva apresentar um perfil que não deixe dúvidas de seu saber"
} 
de "formação profissionalizante", estes professores, sujeitos desta pesquisa, também estarão constantemente se constituindo como docentes pelo exercício da exposição de seus conhecimentos à prática profissional.

Neste sentido, as informações obtidas com esta pesquisa e as análises realizadas indicam uma possível continuidade de estudos para compreender como as experiências formativas, acadêmicas e sociais, destes sujeitos cruzam a sua formação de forma a constituí-lo como professor. E de que forma estas variadas experiências curriculares (aqui entendendo currículo como tudo que corre e ocorre junto à formação do sujeito, acadêmicas e não acadêmicas) contribuem para constituir o ethos docente deste sujeito licenciado. No intuito de compreender essas especificidades formativas que se constituem por um trabalho de interação entre o sujeito e o conhecimento que, conforme Dalla Zen (2017, p.105), "implica, antes de tudo, um processo ativo, uma disponibilidade do sujeito em cuidar de si”, faz-se imprescindível ouvir estes sujeitos egressos em torno de suas memórias, aprendizados, vivências, dores, alegrias. Compreendemos que a formação do sujeito, em que pese a condução de suas ações pela formação curricular de graduação ser igual a de seus colegas, é muito individual e diz respeito à forma intrínseca como ele se relaciona com o conteúdo de forma a torná-lo um aprendizado, um conhecimento, um ethos de sua docência. Neste sentido, acreditamos que há nas experiências formativas do professor, uma função etopoiética, ao considerar que a relação do sujeito com as experiências afeta a "natureza do sujeito, ou melhor dizendo, a sua maneira de agir, o seu êthos" (FOUCAULT, 2010, p. 211). Mas em que medida, de que formas? Com esta pesquisa e os questionamentos suscitados, abre-se outro caminho de estudo, quiçá a partir de entrevistas narrativas, que poderá oferecer novas possibilidades de resposta.

\section{Referências}

BRABO, Gabriela. Formação docente inicial e o ensino ao aluno com deficiência em classe comum na perspectiva da educação inclusiva. Porto Alegre: UFRGS, 2013. 163p. Tese (Doutorado em Educação). Disponível em: http://hdl.handle.net/10183/72692. Acesso em 27 jan2019.

BRASIL. Declaração de Salamanca e linha de ação sobre necessidades educativas especiais. UNESCO, Brasília, 1994. Disponível em http://portal.mec.gov.br/seesp/arquivos/pdf/salamanca.pdf. Acesso em 15jul 2019.

BRASIL. Lei $n^{\circ}$ 9.394, de 20 de dezembro de 1996. Estabelece as diretrizes e bases da educação nacional. Brasília, DF: Presidência da República, 1996. Disponível em http://www.planalto.gov.br/ccivil_03/leis/19394.htm. Acesso em 05abr2020.

BRASIL. Lei $n^{o}$ 10.436, de 24 de abril de 2002. Dispõe sobre a Língua Brasileira de Sinais Libras e dá outras providências. Brasília, DF: Presidência da República, 2002. Disponível em http://www.planalto.gov.br/ccivil_03/leis/2002/110436.htm. Acesso em 05abr 2020. 
BRASIL. Lei $n^{o}$ 12.711, de 29 de agosto de 2012. Dispõe sobre o ingresso nas universidades federais e nas instituições federais de ensino técnico de nível médio e dá outras providências. Brasília, DF: Presidência da República, 2002. Disponível em http://www.planalto.gov.br/ccivil_03/_ato2011-2014/2012/lei/112711.htm. Acesso em 28 ago2019.

BRASIL. Lei 13.146, de 6 de julho de 2015. Institui a Lei Brasileira de Inclusão das Pessoas com Deficiência (Estatuto da Pessoa com Deficiência). Diário Oficial da União 2015; 7 jul. Disponível em http://www.planalto.gov.br/ccivil_03/_ato2015-2018/2015/lei/113146.htm. Acesso em27jul2019.

BRASIL. Secretaria de Direitos Humanos da Presidência da República. Secretaria Nacional de Promoção dos Direitos das Pessoas com Deficiência. Viver Sem Limite - Plano Nacional dos Direitos da Pessoa com Deficiência. Brasília: SDH-PR/SNPD, 2013. Disponível em http://www.planalto.gov.br/ccivil_03/_Ato2011-2014/2011/Decreto/D7612.htm. Acesso em 27 jul2019.

COSTA, Francisco José da; JÚNIOR, Severino Domingos da Silva. Mensuração e Escalas de Verificação: uma Análise Comparativa das Escalas de Likert e Phrase Completion. Revista Brasileira de Pesquisas de Marketing, Opinião e Mídia, v. 15, p.1-16. São Paulo, Brasil, 2014. Disponível em: http://sistema.semead.com.br/17semead/resultado/trabalhosPDF/1012.pdf. Acesso em: 24 set. 2018.

DALLA ZEN, Laura Habckost. O lugar das experiências culturais na constituição de um Ethos Docente. Porto Alegre: UFRGS, 2017. 205p. Tese (Doutorado em Educação). Disponível em http://hdl.handle.net/10183/158270. Acesso em 28 jun 2018.

FABRIS, Eli Terezinha Henn. In/exclusão no currículo escolar: o que fazemos com os “incluídos"? Revista Educação Unisinos, São Leopoldo, v. 15, nº 1, 32-39, jan 2011. Disponível em: http://revistas.unisinos.br/index.php/educacao/article/view/978. Acesso em: 15 ago. 2018.

FERREIRA, Júlio Romero; GLAT, Rosana. Reformas educacionais pós-LDB: a inclusão do aluno com necessidades especiais no contexto da municipalização. In: Souza, Donaldo Bello; Faria, Lia Ciomar Macedo de. (Org.) Desafios da Educação Municipal. Rio de Janeiro: DP\&A, 2003, pg. 372-390.

FOUCAULT, Michel. A hermenêutica do sujeito. São Paulo: Martins Fontes, 2010.

IBGE. PNAD Contínua 2016: 51\% da população com 25 anos ou mais do Brasil possuíam no máximo o ensino fundamental completo. Agência IBGE Notícias, 2013. Disponível em: $<$ https://agenciadenoticias.ibge.gov.br/agencia-sala-de-imprensa/2013-agencia-denoticias/releases/18992-pnad-continua-2016-51-da-populacao-com-25-anos-ou-mais-do-brasilpossuiam-no-maximo-o-ensino-fundamental-completo>. Acesso em: 20 mar. 2019.

KRAEMER, Graciele Marjana. A modulação das condutas das pessoas com deficiência no direito à escola comum brasileira. Porto Alegre: UFRGS, 2017. 202p. Tese (Doutorado em Educação). Disponível em http://hdl.handle.net/10183/168789. Acesso em 03 jan 2018.

LARROSA, Jorge. Notas sobre a experiência e o saber de experiência. Revista Brasileira de educação, nº 19, 20-28. Jan/Fev/Mar/Abr 2002. Disponível em http://www.scielo.br/pdf/rbedu/n19/n19a02.pdf. Acesso em 04 fev 2018.

LOPES, Maura Corcini; RECH, Tatiana Luiza. Inclusão, biopolítica e educação. In: Revista Educação, Porto Alegre, v. 36, n. 2, p. 210-219 mai/ago, 2013. Disponível em: http://revistaseletronicas.pucrs.br/ojs/index.php/faced/article/view/12942. Acesso em: 19 mai. 2018. 
LUNARDI, Márcia Lise. A produção da anormalidade surda nos discursos da Educação Especial. Porto Alegre: UFRGS, 2003. 200p. Tese (Doutorado em Educação). Disponível em http://hdl.handle.net/10183/3444. Acesso em 15maio2018.

MACIENTE, Aguinaldo Nogueira; NASCIMENTO, Paulo A. Meyer M.; SERVO, Luciana Mendes Santos; VIEIRA, Roberta da Silva; SILVA, Carolina Andrade. A inserção de recémgraduados em engenharias, medicina e licenciaturas no mercado de trabalho formal, segundo dados do Enade e da Rais. Radar: tecnologia, produção e comércio exterior, n. 38, p. 7-22, abril, 2015. Disponível em: http://repositorio.ipea.gov.br/handle/11058/4236. Acesso em: 02 jun. 2019.

MENEZES, E. C. P. A maquinaria na produção de subjetividades para uma sociedade inclusiva. São Leopoldo, 2011. 189p. Tese (Doutorado em Educação). Disponível em http://www.repositorio.jesuita.org.br/handle/UNISINOS/3544. Acesso em 04 fev 2019

NÓVOA, António. Para una formación de profesores construida dentro de la profesión. In: Revista de Educación, v. 350, p. 203-218, 2009. Disponível em:

http://www.educacionyfp.gob.es/revista-de-educacion/numeros-revista-educacion/numerosanteriores/2009/re350/re350-09.html. Acesso em: 02 jun. 2019.

ORGANIZAÇÃO DAS NAÇÕES UNIDAS. Convenção sobre os Direitos das Pessoas com Deficiência, aprovada pela Assembléia Geral da ONU. Dezembro de 2006. Disponível em https://nacoesunidas.org/acao/pessoas-com-deficiencia/. Acesso em 20 mai. 2017.

POKER, Rosimar Bortolini; VALENTIM, Fernanda Oscar Dourado; GARLA, Isadora Almeida. Inclusão no ensino superior: a percepção de docentes de uma instituição pública do interior do estado de São Paulo. Psicologia Escolar e Educação, Maringá, v. 22, p. 127-134, 2018. Disponível em: http://dx.doi.org/10.1590/2175-3539/2018/010. Acesso: 08 jun. 2019.

POULIN, Jean-Robert; FIGUEIREDO, Rita Vieira de. Formação inicial de professores para atuarem no contexto das diferenças. REVASF - Revista de Educação da Universidade Federal do Vale do São Francisco, v. 6, p. p. 64-78, 2016. Disponível em http://www.periodicos.univasf.edu.br/index.php/revasf/article/view/37. Acesso em: 05maio2019.

SÁNCHEZ, P. A. Las escuelas son para todos. Siglo Cero, v. 27, n. 2, p. 25-34, 1996. Disponível $\mathrm{em}$ : http://www.inclusioneducativa.org/content/documents/Escuelas_Para_Todos.pdf. Acesso em: 16 abr. 2018.

TERRA, Ricardo Nogueira; GOMES, Claudia Gomes. Inclusão escolar: carências e desafios da formação e atuação profissional. Revista Educação Especial, Santa Maria Santa Maria v. 26, n. 45, p. 109-123, janeiro-abril, 2013. Disponível em:

〈https://periodicos.ufsm.br/educacaoespecial/article/view/5629/pdf $>$. Acesso em: 08 jun. 2019.

TRAVERSINI, C. S. O desencaixe como forma de existência da escola contemporânea. In: $4^{o}$ Seminário Brasileiro de Estudos Culturais e Educação, 4; 2011, Canoas. Apresentado na mesaredonda "Desencaixes da escola contemporânea: desafio a superar?". Disponível em:

https://pt.scribd.com/document/131427038/TRAVERSINI-Clarice-O-desencaixe-como-formade-existencia-da-escola-contemporanea. Acesso em: 13 ago. 2018.

VARGAS, H.; DE PAULA, M. F. C. A inclusão do estudante-trabalhador e do trabalhadorestudante na educação superior: Desafio público a ser enfrentado. Revista Avaliação, Campinas; Sorocaba, SP, v. 18, n. 2, p.459-485, julho, 2013. Disponível em:

http://www.scielo.br/scielo.php?pid=s1414-40772013000200012\&script=sci_abstract\&tlng=pt. Acesso em: 20 mai. 2019.

VEIGA-NETO, Alfredo; LOPES, Maura Corcini. (2007). Inclusão e governamentalidade.

Revista Educação \& Sociedade, v. 28, n. 100. Campinas/SP: CEDES, p. 947-964, outubro, 2007. 
Disponível em: <http://www.scielo.br/scielo.php?script=sci_arttext\&pid=S010173302007000300015>. Acesso em: 02 jun. 2019.

Recebido em 17/06/2019. Aprovado em 15/09/2019. 